\title{
TELEJORNALISMO, TRABALHO E SAÚDE NA COBERTURA DA PANDEMIA DA COVID-19
}

\author{
Paulo Eduardo Silva Lins Cajazeira ${ }^{1}$ \\ José Jullian Gomes de Souza²
}

Resumo:

Neste artigo, propõe-se a investigação da saúde e do trabalho do jornalista atuante na cobertura da pandemia da Covid-19, no primeiro semestre de 2020, na Região Metropolitana do Cariri, sul do Ceará. Parte-se de uma proposta de metodologia quantiqualitativa, exploratória e documental da nova práxis jornalística a partir de protocolos de prevenção ao novo coronavírus. Procurou-se observar como as empresas de comunicação estão lidando com esses protocolos, principalmente com a saúde de seus colaboradores, e com os impactos da crise sanitária no fazer jornalístico relacionados aos procedimentos de coleta de informações e produção de reportagens. A pesquisa concluiu que, dos 23 respondentes ao questionário online, a maioria continua atuante no ambiente de trabalho físico e uma minoria desenvolve o trabalho via sistema home office.

Palavras-chave: Práxis profissionais; Saúde do jornalista; Pandemia; Crise sanitária; Cobertura jornalística.

\begin{abstract}
:
This article aims to investigate the health and the work of the journalists who covered the Covid-19 pandemic, in the first semester of 2020, in the metropolitan area of Cariri, south of Ceará. We start from a proposal of a quanti-qualitative, exploratory and documental methodology of the new journalistic praxis based on prevention protocols for the new coronavirus. We sought to observe how communication agencies have been dealing with those protocols, especially when it refers to the collaborators' health, as well as to the impacts of the health crisis in the journalistic doing related to information gathering procedures and articles production. The research concluded that, out of the 23 people who responded to the online questionnaire, the majority remains working in the physical place and just a small part of it works from home.
\end{abstract}

Keywords: Professional praxis; Journalists health; Pandemic; Health Crisis; Journalistic Coverage.

\section{Introdução}

Esta pesquisa parte de duas importantes questões, as quais nortearam nossas inquietações recentes diante das alterações na rotina do trabalho da imprensa e na saúde dos jornalistas, durante a cobertura da pandemia da Covid-19. A primeira questão corresponde às atuais condições de trabalho do jornalista e a segunda diz respeito aos impactos no fazer jornalístico da cobertura diária da pandemia. Primeiramente

\footnotetext{
1 Professor Associado da Universidade Federal do Cariri (UFCA). Vice-coordenador do Programa de Pósgraduação em Biblioteconomia - UFCA. Pesquisador da Fundação Cearense de Apoio à Pesquisa e Desenvolvimento Científico e Tecnológico (FUNCAP). Líder do Centro de Estudos e Pesquisa em Jornalismo (CEPEJor/UFCA/CNPq). Pós-doutor em Ciência da Comunicação na Universidade da Beira Interior (Portugal). Doutor em Comunicação e Semiótica - PUC de São Paulo. Bacharel em Comunicação Social - PUC do Paraná.

2 Mestre em Biblioteconomia pela Universidade Federal do Cariri. Bacharel em Jornalismo pela Universidade Federal do Ceará. Pesquisador do Centro de Estudos e Pesquisa em Jornalismo (CEPEJor/CNPq/UFCA).
} 
contextualiza-se o problema de pesquisa, culminando na pergunta-problema. Em seguida, explicitam-se as principais escolhas teóricas, os métodos de pesquisa e a análise de orientações realizadas por organismos nacionais e internacionais de imprensa e saúde: Federação Nacional de Jornalistas (FENAJ), Federação Internacional de Jornalismo (FIJ) e Organização Mundial de Saúde (OMS).

Como problema de pesquisa, elencamos o seguinte questionamento: “Como as organizações jornalísticas da região do Cariri cearense têm demonstrado a preocupação com a saúde dos jornalistas de televisão colaboradores durante a cobertura jornalística da pandemia da Covid-19?". A partir disso, enumeramos algumas hipóteses: a) na proporção em que se investem em medidas preventivas como o trabalho remoto (home office); b) realizam a distribuição de Equipamentos de Proteção Individual (EPIs) aos profissionais na linha de frente das reportagens (profissionais de TV, especificamente); c) criação de protocolos de proteção nas atividades externas de produção de reportagem; e d) alteração da rotina de convívio dos jornalistas na redação com o uso de máscaras e outros equipamentos de proteção individual. Conforme nos afirmam Fígaro et al. (2020, p. 19):

O contexto de pandemia da Covid-19 certamente acelerou a transição que alguns setores já ensaiavam de transmutar o local de trabalho para a residência do trabalhador. A situação de emergência em prol da saúde coletiva passou a justificar, desse modo, a forma improvisada que muitos tivemos de assumir do trabalho em casa. 0 improviso é de toda ordem: equipamentos inadequados, falta de softwares, falta de apoio técnico, falta de uma rotina organizada que se precisa inventar, inadequação de móveis e local não ergonômicos, lugar/espaço/ambiente inadequado, porque sobreposto à ambiência que pertence ao espaço privado da casa, do lar. $\mathrm{O}$ isolamento social também retira do trabalho algo fundamental que é a coletividade.

Esses procedimentos fazem os jornalistas estarem fisicamente longe da redação, como parte das orientações de prevenção e distanciamento social dos órgãos de imprensa e saúde. Como nos relatam Fígaro et al. (2020, p. 3), “[...] o afastamento social e o home office foram indicados como ações necessárias para diminuir o impacto da infecção pelo novo coronavírus". Os autores alertam ainda, que nem todos os profissionais da comunicação podem manter o distanciamento social. No exercício profissional, o serviço público da informação exige, muitas vezes, a apuração do fato in loco. Também se cobra a pesquisa para a produção da informação qualificada sobre o produto e a verificação dos dados para traçar políticas de comunicação para as instituições (FíGARO et al., 2020). 
Na divulgação científica, no setor de saúde, seja nos órgãos públicos ou privados, hospitais, ministério, secretarias ou no apoio institucional, os profissionais da comunicação estão atentos, atuantes, presentes. O Brasil tem aproximadamente 145 mil jornalistas profissionais registrados, e, cerca de um terço possui mais de um vínculo empregatício (MICK; LIMA, 2013). Outros dados importantes do estudo realizado pelos pesquisadores Mick e Lima (2013), é o perfil do jornalista brasileiro, o qual compreende, entre outros elementos, as seguintes características: idade (59\% na faixa de 18 a 30 anos); mulheres $(63,7 \%)$, homens $(36,3 \%)$; prioritariamente se reconhecem como brancos $(72,2 \%)$; 9 entre 10 jornalistas são profissionais formados em instituições de ensino superior; e 25,2\% desses profissionais são filiados a sindicatos da categoria.

\section{A descrição do objeto de análise: contextualização}

Desenvolvemos uma pesquisa com um grupo de jornalistas atuantes em Juazeiro do Norte, Crato e Barbalha - cidades-polo da Região Metropolitana do Cariri ${ }^{3}$ cearense -, entre os meses de maio e junho de 2020. A população dessas três cidades, consideradas como cidades médias, de acordo com o IBGE (2017) soma 601.817 habitantes. No estudo Rede Urbana do Brasil ${ }^{4}$, as cidades médias estão presentes nas categorias de Centros Regionais, Centros Sub-regionais 1 e Centros Sub-regionais 2.

0 que diferencia essas categorias urbanas são: a centralidade (área de influência abrangência regional do fluxo de bens e serviços que têm origem no centro urbano); as relações internacionais (presença de grandes empresas e corporações, redes complexas de serviços modernos que fortalecem o papel de centros decisórios); a escala da urbanização (dimensão do processo de urbanização em relação ao conjunto da rede urbana brasileira); a complexidade e diversidade da economia urbana (existência de setores econômicos diferenciados e nível de articulação setorial); e a diversificação do setor terciário e funcionalidade (diversificação das atividades de serviços e funções urbanas específicas).

\footnotetext{
${ }^{3} \mathrm{O}$ conjunto urbano da Região Metropolitana do Cariri (RMC) está situado a uma distância média de $600 \mathrm{~km}$ das duas metrópoles regionais nordestinas mais próximas, Fortaleza e Recife. As três cidades principais (Juazeiro do Norte, Crato e Barbalha) mantêm vínculos estreitos tanto em termos de proximidade territorial quanto relacional, sobretudo pela relação de complementaridade socioeconômica no Cariri cearense. Essa região metropolitana é, atualmente, composta por nove municípios: Juazeiro do Norte, Crato, Barbalha, Jardim, Missão Velha, Caririaçu, Farias Brito, Nova Olinda e Santana do Cariri. A RM do Cariri possui uma área total de 5.456,01 Km2 (IBGE, 2010).

${ }^{4}$ IPEA. Configuração atual e tendências na rede urbana do Brasil, 2020. (Série caracterização e Tendências da Rede Urbana do Brasil, 1). Convênio Ipea, IBGE, Unicamp/IE/Nesur.
} 
O município de Juazeiro do Norte possuía 79\% do Produto Interno Bruto (PIB), em 2012 voltado ao setor de serviços, seguido de indústria (17\%) e agropecuária (4\%). Em relação à urbanização, a taxa de urbanização é de $70 \%$, segundo relatório do Instituto Brasileiro de Geografia e Estatística (IBGE, Juazeiro do Norte). O Ceará apresenta um dos maiores índices de contaminação do país pela Covid-19. O sul do estado possui uma curva em ascendência nos casos de contaminação pela doença registrados no primeiro semestre

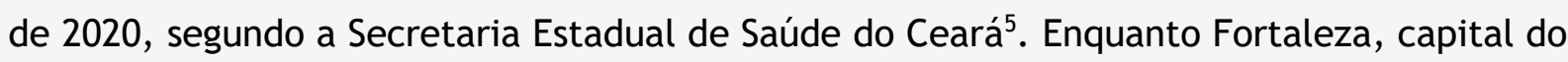
estado do Ceará, apresenta uma queda nos índices de contaminação, a região do Cariri (sul do Ceará) tem apresentado índices de contaminação cada vez maiores e preocupantes em relação ao número de doentes, isolamento social e de óbitos.

As cidades foram também escolhidas pela proximidade acadêmica e profissional dos pesquisadores. Essa escolha não foi feita visando necessariamente uma comparação, mas mostrar que é possível a existência de várias realidades no país, no que se refere à saúde do jornalista na cobertura da pandemia.

Propusemos, a partir dos protocolos de prevenção do trabalho do jornalista de televisão, o desenvolvimento de um guia de prevenção ao novo coronavírus na práxis jornalística em televisão. Esse documento levantou a necessidade de orientação e prevenção aos profissionais durante o período de crise sanitária.

\section{A Covid-19}

Segundo informações do Ministério da Saúde do Brasil, a Covid-19 é uma doença causada pelo coronavírus SARS-CoV-2 que apresenta um quadro clínico que varia de infecções assintomáticas a quadros respiratórios graves. De acordo com a OMS, a maioria dos pacientes com Covid-19 (cerca de $80 \%$ ) podem ser assintomáticos e cerca de $20 \%$ dos casos podem requerer atendimento hospitalar por apresentarem dificuldade respiratória e, desses casos, aproximadamente $5 \%$ podem necessitar de suporte para o tratamento de insuficiência respiratória (suporte ventilatório).

A maioria das pessoas se infecta com algum tipo de coronavírus, ao longo da vida, sendo as crianças pequenas mais propensas a se infectarem com o tipo mais comum do vírus. Os coronavírus mais comuns que infectam humanos são o Alpha Coronavírus 229E e

\footnotetext{
${ }^{5}$ As informações são do boletim epidemiológico da Secretaria Estadual da Saúde (SESA), divulgado no dia 21 de novembro de 2020. A região do Cariri registrou, até 21 de novembro de 2020, 55.857casos confirmados (representando um acréscimo de $1,2 \%$ no total de casos) e 1.122 óbitos.
} 
NL63 e Beta Coronavírus OC43, HKU1. Os sintomas da Covid-19 podem variar de um simples resfriado até uma pneumonia severa, sendo os sintomas mais comuns: tosse, febre, coriza, dor de garganta e dificuldades para respirar.

A transmissão ocorre de uma pessoa doente para outra, por contato próximo por meio de toque, aperto de mão gotículas de saliva, espirro, tosse e catarro; ou ainda por objetos ou superfícies contaminadas, como celulares, mesas, maçanetas, brinquedos, teclados de computador etc.

\section{O telejornalismo local}

O jornalismo tem como uma das suas premissas a prestação de serviço à sociedade, a partir das notícias que são veiculadas nas mais diversas mídias. Dentre estas encontra-se o telejornalismo, um tipo particular do fazer jornalístico que dialoga com os elementos textuais, sonoros e imagéticos. Assim, diante das telas - hoje, num cenário convergente e em mobilidade -, o telejornalismo está presente na vida dos sujeitos sociais mediante os acontecimentos e a sua representação para o público.

Assim, conforme salientam Coutinho e Mota (2010, p. 65), “[...] os noticiários de TV cumprem uma função pública e buscam nos cidadãos que representam a cada edição, ou nas imagens que os jornalistas constroem do público, princípios legitimadores do conhecimento socialmente produzido a cada edição". E no caso dos telejornais locais, que estão presentes dos cidadãos, no dia a dia, a criação e a manutenção de um vínculo se apresenta como um dos grandes desafios.

O telejornalismo se configura como um eixo central de representação da sociedade, dos seus problemas, dramas e enfrentamos cotidianos. De acordo com Vizeu e Correia (2008) há uma necessidade do telejornal "falar" por esses sujeitos, ser a voz do enfrentamento pelos seus direitos. Pois, a televisão e o telejornalismo têm a responsabilidade de fornecer ao telespectador uma programação que tanto o ajude a compreender as dinâmicas locais partindo para o global, a partir das ligações que aproximem a comunidade dos amplos sistemas (BAZI, 2001).

Desse modo, o desafio do telejornalismo local e regional não é somente apresentar uma programação de qualidade, mas, sobretudo, oferecer os seus telespectadores essa relação de proximidade, de intimidade: a criação de um vínculo de pertencimento. Com isso, Bazi (2001) explica que as identidades são moldadas a partir das vivências diárias 
dessas pessoas. E, que esse espaço regional se configura como um lugar específico no qual a população dessa região se sente inserida e partilha de sentidos, cujos espaços thes são familiares.

Neste sentido, entendemos que o jornalismo local proporciona uma valorização do conjunto da sociedade que se apresenta como uma oportunidade de debater questões próximas do público. Assim, o telejornal funciona como um instrumento que influência na construção do sujeito, seu comportamento e na reprodução da dinâmica de vida a partir do sentimento de pertencimento em um território específico. Desse modo, a televisão, como reflete Wolton (1996), é uma atividade que suscita a participação e fornecedora de representação e laços sociais com os sujeitos.

Acerca do telejornalismo, especificamente o local, entendemos que ele é uma dessas atividades televisivas que proporciona ao público a visualização da sua representação na tela da TV seja através de programas que retratem seus costumes, seja em noticiários com reportagens sobre os problemas da cidade, do bairro e a sua constituição histórica. Diante desse processo de construção e representação de uma identidade regional televisiva, Bazi (2001) alega que a conquista da audiência de uma emissora regional passa pela questão da qualidade de seus programas e da sua credibilidade junto ao público.

\section{O jornalismo em transformação frente a pandemia da Covid-19}

O jornalismo passa por consideráveis mutações, desde a última década, relacionadas ao advento da tecnologia digital, o que contribuiu e ampliou o trabalho da imprensa. Diariamente, surgem novas tecnologias que geram novos processos ou viceversa, potencializando assim a criação de produtos com o envolvimento de novos personagens durante os processos e maneiras de captação, produção, exibição e consumo da informação.

Todas essas mudanças, consequentemente, precisam ser acompanhadas, uma vez que seu objetivo é atuar nesse cenário de mutações constantes e disformes pela qual perpassa o jornalismo, em especial o telejornalismo. No entanto, a velocidade em que estas alterações acontecem está cada vez maior, as transformações se dão de maneira cada vez mais aceleradas, e ininterruptamente. Em vista disso, Nilson Lage afirma que é necessário atualizar o conhecimento de mundo e por causa dessas mutações, cada vez mais 
aceleradas, o mundo requer um conhecimento que "não é mais possível de adquirir em currículos escolares" (LAGE, 2003, p. 22).

Com o advento da cobertura jornalística sanitária não programada pela imprensa, apesar dos fundamentos do jornalismo permanecerem inalterados, como a objetividade, o compromisso com a verdade e a prestação de serviços, entre outros, a realidade profissional não é mais a mesma desde início de 2020. Eis o desfio dos jornalistas diante da crise sanitária protagonizada pela pandemia do Covid-19: se reinventar respeitando os protocolos nacionais e internacionais de saúde.

Giacomelli, Giacomelli, Grafolin (2020, p. 4) afirmam que “[...] na área da saúde, a informação é cada vez mais importante considerando o avanço tecnológico que visa nos habilitar para uma autogestão da saúde". Zhao e Zhang (2017) apresentam uma definição específica para informação de saúde, retirada do U.S National Library of Medicine, que a define como temas de saúde em geral, medicamentos e suplementos, populações específicas, genética, saúde ambiental e toxicologia, ensaios clínicos e literatura biomédica.

Para Nutbeam (2000), a literacia em saúde é uma das consequências da promoção da saúde, que se refere a uma série de ações públicas direcionadas para melhorar o controle das pessoas sobre todas as variáveis que influenciam na saúde. 0 autor ainda salienta que existem diferentes níveis de literacia em saúde:

1) Funcional: transmissão de informações factuais sobre saúde, riscos e utilização de serviços através de canais de comunicação existentes, tanto interpessoal como midiático;

2) Interativo: também inclui a transmissão de informações acrescido de oportunidades de desenvolver habilidades em um ambiente com suporte. Utiliza diferentes canais para a comunicação de necessidades específicas de saúde, criação de grupos comunitários de autoajuda e apoio social;

3) Crítico: inclui as características dos níveis acima, acrescentando o fornecimento de informações sobre determinantes sociais e econômicos da saúde e oportunidades para alcançar mudanças políticas e/ou organizacionais.

No caso do telejornalismo, esta realidade da literacia midiática utiliza-se dos três níveis - funcional, interativo e crítico -, pois o telejornalismo, mesmo fazendo uma cobertura temática, procura oferecer ao público inúmeras informações construídas por 
meio de diferentes enquadramentos e pontos de vista, orientados por um único fio condutor de narrativas na cobertura jornalística da crise sanitária. Por vezes, no entanto, transparece ao leitor, ouvinte, telespectador ou internauta, uma cobertura monotemática.

Como destaca Grafolin (2017), o processo jornalístico de comunicar saúde não significa apenas promover cuidados na área, pois as mensagens possuem diversas finalidades: evitar riscos, prevenir doenças, sugerir mudanças de comportamento em benefício do indivíduo e da comunidade na qual está inserido, recomendar medidas preventivas e, principalmente, atuar na formação da literacia em saúde.

Além dos aspectos técnicos, os profissionais de imprensa tiveram que adaptar os termos técnicos ao texto jornalístico, quais sejam: confinamento, isolamento social, quarentena, achatamento da curva, EPIs, Covid-19, coronavírus, distanciamento social, comorbidade, entre outros.

\section{Metodologia}

A metodologia utilizada foi de cunho quanti-qualitativo, exploratória-descritiva e documental. Para atingir as metas do estudo, foram considerados dois instrumentos como determinantes: a) formulário on-line direcionado aos jornalistas de Juazeiro do Norte, Crato e Barbalha; e b) desenvolvimento de um Guia para jornalistas de prevenção à Covid19, com informações documentais da FENAJ, FIJ e OMS. O instrumento de coleta foi criado pela equipe de investigadores desta pesquisa. No desenvolvimento do questionário, foram elaboradas perguntas fechadas, condicionantes ao nível de resposta do inquirido e, ao final, uma pergunta aberta, considerando-se as consistências lógicas entre as perguntas que garantiriam a qualidade na análise da coleta de dados. Para isso, foram estudados, anteriormente, alguns modelos de questionários desenvolvidos pela FENAJ e FIJ.

De posse dos endereços de e-mail dos jornalistas, realizou-se o envio do formulário on-line na plataforma Google Forms, dividindo o público-alvo em três categorias: sexo, formação e atuação profissional. Tal estratégia torna possível não só a garantia do acompanhamento das atividades, mas os aspectos de cumprimento dos protocolos sanitários pelas empresas de comunicação locais.

O formulário online enviado para os jornalistas da região do Cariri cearense, tem como objetivo identificar e verificar as medidas de proteção que as empresas de comunicação estão realizando acerca da saúde desses profissionais, diante a pandemia da 
Covid-19. Enviado por e-mail, o formulário coletou 23 respostas entre o período de 29 de maio a 19 de junho de 2020, e está estruturado em 8 questões e informações iniciais sobre a faixa etária, sexo e tipo de veículo em que trabalha.

\section{Análise dos dados}

Do total de repostas alcançadas - 39, 1\% dos jornalistas têm idade entre 25 a 29 anos; $26,1 \%$ têm até 24 anos e a mesma porcentagem para jornalistas com idade entre 30 a 39 anos; e 8,7\% têm de 40 a 49 anos. Assim, visualiza-se que a maioria dos jornalistas possui faixa etária entre 24 e 29 anos. Esse dado pode ser atribuído à implementação do único curso de Jornalismo existente na região, ofertado, inicialmente pela Universidade Federal do Ceará - campus Cariri, em 2010 - desmembrado da UFC, com a criação da Universidade Federal do Cariri (UFCA), a partir do Programa de Apoio a Planos de Reestruturação e Expansão das Universidades Federais (REUNI), em 2013. Em relação ao sexo, 60,9\% dos participantes são jornalistas homens e 39,1\% são mulheres, demonstrando uma paisagem profissional formada, majoritariamente, por uma classe masculina.

Identificou-se que a maioria dos profissionais estão situados em empresas jornalísticas voltadas para o radiojornalismo $(39,1 \%)$, uma vez que na região do Cariri cearense o rádio possui uma presença forte e prestigiada, abarcando grande parte dos profissionais. Em seguida, temos os veículos online $(26,1 \%)$, assessorias de comunicação ou imprensa $(21,7 \%)$, e os jornalistas que trabalham em televisão (13\%). Na região, temos 2 (duas) emissoras de TV: a afiliada da Rede Globo de Televisão Verdes Mares Cariri, oriunda da expansão da matriz situada na cidade de Fortaleza (TV Verdes Mares), e outra pertencente à cidade de Juazeiro do Norte $^{6}$, a TV Verde Vale ${ }^{7}$.

A primeira questão identificou se os jornalistas estão trabalhando de modo presencial ou em domicílio durante a pandemia. De acordo com os dados obtidos observamos uma predominância do trabalho domiciliar com $82,6 \%$ e $17,4 \%$ de modo presencial. Uma realidade que se configura com as recomendações da FENAJ, que recomenda a realização de teletrabalho (home office) na maioria dos casos possíveis.

\footnotetext{
${ }^{6}$ Afiliada da Rede Globo no interior do estado do Ceará, a TV Verdes Mares Cariri está em operação no canal 9 , desde 1 de outubro de 2009. A partir do ano de 2017, a emissora para a transmitir a segunda edição do CETV diretamente produzida no Cariri.

7 É uma TV comercial, operando no canal 13 desde 24 de março de 2006. Se ocupa em realizar transmissões e acontecimentos na região do Cariri cearense e se apresenta como um dos campos de atuação telejornalística para a cidade de Juazeiro do Norte. Visto que, existem apenas duas emissoras de TV na região.
} 
Na segunda questão, os jornalistas foram interrogados sobre as condições de saúde e segurança em seus respectivos trabalhos. Das 23 respostas, $87 \%$ afirmaram que as empresas se preocupavam em ofertar condições de saúde e segurança, e 13\% estavam trabalhando mesmo sem a empresa proporcionar tais cuidados. Essa visualização de dados explicita, em parte, a precariedade estrutural de algumas empresas jornalísticas para com a atenção e o cuidado com o seu quadro profissional.

Já na terceira questão, os jornalistas responderam sobre a quantidade de EPIs e se eram suficientes para a troca e higienização. Para $60,9 \%$ as condições de trabalho se afirmam como positiva, e 39,1\% queixaram-se sobre a não disponibilização dos EPIs. Numa comparação com a questão anterior, entende-se que há maior disparidade nas respostas sobre a disponibilização de EPIs. Se $87 \%$ dos jornalistas afirmam que as empresas dispõem de cuidados com a saúde dos seus jornalistas, e na resposta afirmativa sobre os EPIs, apenas $60,9 \%$ dessas mesmas empresas fazem essa disponibilização, tem-se um quadro no qual os cuidados e condições de saúde dos seus profissionais, os EPIs não são necessariamente contemplados.

Acerca de quais EPIs estavam sendo disponibilizados, na quarta questão, temos os seguintes dados: o álcool gel $(60,9 \%)$ e a máscara $(47,8 \%)$ são os equipamentos mais disponibilizados pelas empresas jornalísticas. Já a luva, EPI que tem sido utilizado mais por empresas internacionais, não obteve tanta aderência, ao menos no recorte desta pesquisa, representando $13 \%$ das respostas.

Destaca-se que uma porcentagem elevada de profissionais destacou a ausência de equipamentos disponibilizados $(34,8 \%)$, o que nos possibilita compreender que eles estão atuando sob o risco de contrair o novo coronavírus. A quinta questão versava sobre as melhorias nas condições de trabalhos dos jornalistas pelas organizações às quais pertenciam, com o intuito de prevenir o contágio da Covid-19 em suas rotinas de trabalho. Dentre as respostas, 43,5\% responderam que poderiam ser melhores, $26,1 \%$ estão satisfeitos, e 30,4\% não souberam avaliar. A partir dos dados, a leitura que podemos realizar é que os jornalistas gostariam que as melhorias existissem ou fossem feitas.

Em conjunto com os dados quantitativos, os jornalistas foram perguntados sobre as sugestões que poderiam acarretar uma melhora de tais condições de segurança do trabalho. Todas as respostas obtidas tratavam sobre a disponibilização de mais materiais básicos de segurança como álcool gel e máscara, ou mesmo de maior quantidade de material. Ou seja, ainda que a organização disponibilize estes equipamentos de proteção, os jornalistas relataram que são insuficientes. 
A sexta questão tratou sobre o nível de pressão (estresse, cobrança por resultados, sobrecarga/acúmulo de trabalho). De acordo com os dados, $82,6 \%$ dos jornalistas responderam afirmativamente sobre o aumento da pressão no trabalho, e 17,4\% disseram não ter sentido uma sobrecarga. Dada a porcentagem, observamos que essa pressão pode estar atrelada ao fluxo de informações que tem sido intensificado durante a pandemia.

A próxima questão verificou os cuidados das empresas jornalísticas com os profissionais pertencentes ao grupo de risco (indivíduos acima de 60 anos e portadores de doenças crônicas como diabetes, hipertensão e asma). Apesar da grande maioria afirmar que as empresas têm demonstrado certa preocupação e adotado medidas de segurança $(73,9 \%), 26,1 \%$ das empresas de comunicação na região do Cariri cearense não seguem o mesmo exemplo. Ainda que nesta pesquisa não se tenham identificado jornalistas pertencentes ao grupo de risco, outros profissionais que integram a equipe e/ou empresa podem configurar o quadro de profissionais do grupo de risco em atividade, atualmente.

A última questão do formulário identificou se o jornalista ou alguém da redação/empresa tinha sido infectado pelo novo coronavírus. Conforme os dados, 95,7\% dos profissionais marcaram "não" como resposta e 4,3\%, ou seja, somente 1 (um) profissional respondeu saber da existência de um caso em seu ambiente de trabalho. Nesse sentido, estes dados nos possibilitam refletir sobre como as empresas jornalísticas da região do Cariri cearense têm cuidado da saúde física e mental dos seus jornalistas.

A partir desses dados de infectados é possível inserir um importante questionamento: a subnotificação dos dados reais, bem como o nível de testagens que estão sendo realizados no Brasil. Ou seja, ainda que a reposta obtida demonstre um baixo teor de infecção nas redações do Cariri cearense, os dados podem se projetar maiores do que o afirmado pelos participantes da pesquisa. Assim, como o fornecimento de dados reais pelas organizações jornalísticas.

Diante das questões analisadas quantitativamente, é preciso refletir sobre a questão qualitativa das informações obtidas com o formulário. A construção da figura da jornalista está relacionada, por exemplo, com as seguintes palavras: coragem, destemor, risco e disposição. Dentro desse imaginário, relacionando com o modo que as empresas jornalísticas estão lidando com os seus profissionais, entendemos que a falta de disponibilização de EPIs (em caráter suficiente) demonstra que culturalmente os jornalistas são profissionais feitos para "correr tais riscos", como pode ser observado no contexto da pandemia. 
A partir desse posicionamento das empresas, frente a questão da Covid-19 e do trabalho profissional dos jornalistas, parece reforçar tal imaginário que vem sendo identificando culturalmente na sociedade brasileira. Uma vez que, no cenário atual a atuação jornalística tem se mostrado cada vez mais necessária diante o volume informacional, as novas práticas adotadas para a realizar da cobertura jornalística cotidiana, especialmente pelos jornalistas de televisão.

De acordo com a FENAJ, o Sindicato dos Jornalistas Profissionais do Ceará (SINDJORCE) enviou às empresas um documento com 19 medidas a serem adotadas de modo emergencial (CORONAVÍRUS,2020). Neste documento estão explicitados os procedimentos que devem ser tomados pelas empresas, corroborando para que as/os seus profissionais estejam seguros e tenham condições mínimas de trabalho. E também, segundo a pesquisa: "Como trabalham os comunicadores em tempos de pandemia da Covid-19?", realizada pelo Centro de Pesquisa em Comunicação e Trabalho (CPCT) da Universidade de São Paulo (USP) de 5 a 30 de abril de 2020.

Os meios de trabalho mais utilizados pelos comunicadores são computadores (100\%) com conexão de internet doméstica (95\%) e smartphones (93\%) de propriedade dos trabalhadores (81,6\%). Quanto à organização de tarefas, observa-se um fenômeno de plataformização do trabalho, que passa a se desenvolver em redações virtuais através de aplicativos de mensagens instantâneas e de ordenamento de tarefas, além de serviços de e-mail. Segundo a maioria dos participantes $(65,8 \%)$, as empresas para as quais trabalham adotaram medidas preventivas suficientes para garantir a segurança dos profissionais.

Dessa forma, é possível afirmar que as empresas de comunicação da região do Cariri cearense estão em consonância com as recomendações da Fenaj e do Sindjorce. Os jornalistas têm recebido assistência e a grande maioria está trabalhando em home office, porém, há um aumento considerável da carga horária de trabalho diário. Os jornalistas têm executado um importante papel em manter o público informado durante a cobertura jornalística em meio à pandemia ocasionada pela Covid-19. Esses integrantes da mídia estão enfrentando uma enorme quantidade de pressão e tensão, e sendo expostos a infecções por meio do deslocamento casa-trabalho, viagens, produção de reportagens e entrevistas nas ruas e locais em que se encontram trabalhando. 


\section{Guia para jornalistas de televisão na cobertura da Covid-19}

Diante desse cenário atual, que tem como prerrogativa o estabelecimento de diretrizes para a prevenção ao novo coronavírus, elaboramos um manual, especificamente, para o jornalista de televisão. O intuito é contribuir para minimização dos danos à saúde desse profissional, com orientações das normas, possibilitando a realização das suas funções a partir de um caráter preventivo. O guia está dividido em três partes: préprodução, produção e segurança do equipamento, com o passo a passo sobre os cuidados que os jornalistas devem manter.

\section{Pré-Produção}

\section{Passo 1}

À equipe de reportagem, no caso das equipes formadas - repórter, cinegrafista e motoristas -, é necessário fornecer o kit completo, que é formado por luvas descartáveis, máscaras faciais e material para a proteção integral dos microfones utilizados no ambiente externo como, por exemplo, papel filme. São materiais simples e necessários, que visam a proteção da equipe de gravação.

Seria desejável que esses kits usados pelas equipes dos laboratórios de Jornalismo saíssem com microfones sem fio, porque o cabo geralmente cai no chão e é então depositado com o restante do kit na bolsa de trabalho. Luvas e máscaras devem ser trocadas a cada turno e não usadas repetidamente até que se quebre, como é o caso. Também é essencial que o equipamento seja higienizado adequadamente, a cada nova gravação.

\section{Passo 2}

Para minimizar o risco de exposição e, sempre que possível, entrevistas devem ser realizadas, preferencialmente por telefone ou online, e não pessoalmente. Até os jornalistas mais experientes podem ter problemas psicológicos ao reportar sobre o surto de Covid-19. 


\section{Passo 3}

O distanciamento entre o repórter e o entrevistado é essencial nas gravações. Conforme orientação das Organização Mundial de Saúde, a distância de um metro já é o suficiente, o equivalente aos dois braços abertos.

\section{Passo 4}

Evite infecções e infectar os outros, portanto, enumeramos alguns locais que julgamos não optarem por gravar durante o período da pandemia:

1) qualquer tipo de estabelecimento de saúde;

2) um lar para idosos;

3) a casa de uma pessoa doente, alguém com problemas de saúde ou alguém que possa estar grávida;

4) necrotério, crematório ou serviço funerário;

5) zona de quarentena, isolamento ou bloqueio;

6) uma habitação urbana densamente lotada (favela, por exemplo).

\section{Produção}

\section{Passo 1}

Mantenha especial cuidado e uma distância mínima de pelo menos 2 metros, quando em contato com aqueles que apresentam sinais ou sintomas de doenças respiratórias, como tosse e espirros. Evite apertar as mãos, abraçar e/ou beijar.

\section{Passo 2}

Tente ficar em ângulo com a pessoa durante uma entrevista, em vez de ficar de frente, mantendo sempre os 2 metros ou mais de distância recomendados. 
Passo 3

Mantenha uma distância mínima segura ao entrevistar idosos, pessoas com problemas de saúde subjacentes, pessoas próximas a indivíduos sintomáticos, profissionais de saúde que tratam pacientes com Covid-19, ou trabalhadores em locais de alto risco.

\section{Passo 4}

Sempre cubra a boca e o nariz ao tossir e espirrar. Se você tossir ou espirrar em um lenço de papel, descarte-o imediatamente de maneira segura e apropriada. Lembre-se de lavar bem as mãos depois.

\section{Segurança do equipamento}

O potencial de espalhar a Covid-19 através de equipamentos contaminados é real. Um rigoroso regime de limpeza e desinfecção deve ser implementado e respeitado o tempo todo:

a) use microfones direcionais a uma distância segura;

b) sempre que possível, use equipamentos móveis em vez daqueles com cabos;

c) se possível e prático, coloque algum tipo de proteção / proteção plástica ao redor do equipamento ao usá-lo. Isso minimizará a área de superfície do equipamento que pode ficar contaminada e será mais fácil de limpar e desinfetar;

d) leve consigo baterias sobressalentes totalmente carregadas e evite carregar qualquer coisa no local, pois esse é um item adicional que pode ser contaminado;

e) certifique-se de que todo o equipamento seja descontaminado novamente ao devolvê-lo;

f) se estiver usando um veículo para a tarefa, assegure-se de que o interior receba uma limpeza profunda antes e após qualquer tarefa de uma equipe treinada adequadamente;

g) deve-se prestar atenção especial às maçanetas das portas, volante, alavanca de câmbio, alavanca do freio de mão, espelhos retrovisores, apoios de cabeça, cintos de segurança, painel de controle e abaixador de janelas. 


\section{Considerações finais}

A realização deste estudo oportunizou a observação e compreensão das atuais práxis jornalísticas, cujo recorte ocorre mediante a realidade da cobertura jornalística sobre a Covid-19 e a saúde dos jornalistas na região do Cariri cearense. Em diálogo com uma cobertura de guerra, o Jornalismo, as empresas midiáticas e os profissionais da informação têm vivenciado, neste primeiro semestre de 2020, grandes desafios para o desenvolvimento da sua missão: levar a informação para os cidadãos. Em meio a uma pandemia, são vários os desafios que esses profissionais enfrentam: pressão, alterações das rotinas, medo do contágio e propagação, instabilidade profissional, dificuldades com a apuração, fornecimento de dados, entre outros.

Identifica-se também a importância da sua atuação jornalística na cobertura da Covid-19, em meio aos processos de desinformação, fake news e informações que circulam sem a devida checagem necessária. A legitimação da profissão e do profissional tem se demonstrado fundamental e crucial, não apenas apresentando dados e estatísticas corretas mas, principalmente, revelando, ainda mais, o lado humanístico do jornalismo e a sua função social. Portanto, é mais do que necessário chamar a atenção de todos para a necessidade em discutir sobre a saúde dos jornalistas, visto que tem se acompanhado, com pesar, a morte de inúmeros colegas de profissão, no atual momento marcado por incertezas e sonhos interrompidos, por familiares e amigos em luto.

Desta forma, esta pesquisa apresentou que a atividade jornalística não foi paralisada, mas houve transformações e mudanças necessárias: trabalho remoto (home office) intensificado para a preservação da saúde dos jornalistas; uso de EPIs para jornalistas que estão trabalhando nas redações e/ou a campo, como no caso dos jornalistas de televisão; necessidade de afastamento da relação jornalista-personagem, sobretudo no momento da entrevista; e entrevistas remotas realizadas via videoconferência, que já eram utilizadas, porém foram intensificadas.

Acerca da cobertura jornalística e a saúde dos jornalistas na região do Cariri cearense identificamos que a grande maioria está trabalhando de modo remoto, e que os jornalistas que estão em modo presencial destacaram a necessidade de maior atenção na disponibilização de EPIs, para que o mesmo material não seja utilizado por muito tempo podendo-se fazer as trocas necessárias. Através do formulário on-line, também pôde ser averiguado o aumento da pressão neste momento de pandemia, com estresse, cobrança 
por resultados e sobrecarga/acúmulo de trabalho: fato que pode ser atribuído à velocidade de informações que circulam cotidianamente, no mesmo sentido em que se deseja transmiti-las às suas audiências.

Assim, a preocupação com os jornalistas, diante o recorte deste estudo, relacionase com a mesma preocupação demonstrada pela Fenaj em âmbito nacional e o Sindjorce, no âmbito do estado do Ceará. Nessa perspectiva, a elaboração de um guia de prevenção ao novo coronavírus na práxis jornalística em televisão fortalece a preocupação e evidencia os cuidados com a saúde desses profissionais, não apenas para a aplicação e usabilidade na região do Cariri cearense, mas como suporte de apoio para as demais realidades de outros estados e regiões do Brasil.

\section{Referências}

BAZI, R. E. R. TV regional: trajetória e perspectivas. Campinas: Alínea, 2001.

CORONAVÍRUS. Sindjorce oficia empresas sobre medidas para proteger jornalistas. 2020. Disponível em: http://www.sindjorce.org.br/coronavirus-sindjorce-oficia-empresas-sobremedidas-para-proteger-jornalistas/. Acesso em: 06 jul. 2020.

COUTINHO, I.; MOTA, J. Telejornalismo a serviço do público: a voz do povo em cena. Revista FAMECOS, Porto Alegre, v. 17, n. 1, p. 65-73, janeiro/abril, 2010.

FEDERAÇÃO NACIONAL DOS JORNALISTAS. Portal fenaj.org.br. Disponível em: http://www.fenaj.org.br/. Acesso em: 12 de mar de 2020.

FIGARO, R. et al. Como trabalham os comunicadores na pandemia do Covid-19? 2020. Disponível em: http://revistatdh.org/index.php/Revista-TDH/article/ view/76. Acesso em: 03 jul. 2020.

GIACOMELLI, E.; GIACOMELLI, F.; GRAFOLIN, T. Saúde nos dispositivos móveis: análise das apps sobre Covid-19 dos Governos do Brasil e de Portugal. 2020. Disponível em: http://revistas.unama.br/index.php/ asasdapalavra/article/view/2126/PDF. Acesso em: 16 jul 2020.

GRAFOLIN, T. Narrativas sobre saúde nos jornais do interior de Portugal. In: CONGRESSO DA AGACOM - ASOCIACIÓN GALEGA DE INVESTIGADORES E INVESTIGADORAS DE COMUNICACIÓN, I, 2017, Universidade de Santiago de Compostela. Anais [...], Santiago de Compostela, Espanha, 2017. 
INSTITUTO BRASILEIRO DE GEOGRAFIA E ESTATÍ́STICA - IBGE. Juazeiro do Norte. 2017. Disponível em: https://cidades.ibge.gov.br/brasil/ce/juazeiro-do-norte/panorama. Acesso em: 10 fev. 2018.

INSTITUTO BRASILEIRO DE GEOGRAFIA E ESTATÍ́STICA - IBGE. Portal ibge.gov.br. Disponível em: http://www.ibge.gov.br/. Acesso em: 12 mar. 2020.

INSTITUTO DE PESQUISA ECONÔMICA APLICADA - IPEA. Portal ipea.gov.br. Disponível em: http://www.ipea.gov.br/. Acesso em: 12 mar. 2020.

LAGE, N. A reportagem: teoria e técnica de entrevista e pesquisa jornalística. São Paulo: Record, 2003.

MICK, J.; LIMA, S. Perfil do jornalista brasileiro: características demográficas, políticas e do trabalho jornalístico em 2012. Florianópolis: Insular, 2013.

NUTBEAM, D. Health literacy as a public health goal: a challenge for contemporary health education and communication strategies into the 21st century. Health Promotion International, v. 15, n. 3, p. 259-267, 2000.

ORGANIZAÇÃO MUNDIAL DA SAÚDE. Portal who.int. Disponível em: https://www.who.int/. Acesso em: 15 mar. 2020.

SECRETARIA ESTADUAL DE SÁUDE. Portal ceara.gov.br. Disponível em: http://www.ceara.gov.br/. Acesso em: 10 mar. 2020.

SINDICATO DOS JORNALISTAS NO CEARÁ. Portal sindjorce.org.br. Disponível em: http://www.sindjorce.org.br/. Acesso em: 06 jul. 2020.

UNIVERSIDADE FEDERAL DO CARIRI. Portal UFCA. Disponível em: http://www.ufca.edu.br/. Acesso em: 10 mar. 2020.

VIZEU, A. E.; CORREIA, J. C. A construção do real no telejornalismo: do lugar de segurança ao lugar de referência. In: VIZEU, Alfredo Eurico (org.). A sociedade do telejornalismo. Petrópolis: Vozes, 2008.

WOLTON, D. Elogio do grande público: uma teoria crítica da televisão. São Paulo: Ed. Ática, 1996.

ZHAO, Y.; ZHANG, J. Consumer health information seeking in social media: a literature review. Health Information \& Libraries Journal, v. 34, n. 4, p. 268-283, 2017. 


\section{Como citar este artigo}

CAJAZEIRA, Paulo Eduardo Silva Lins; SOUZA, José Jullian Gomes de. Telejornalismo, trabalho e saúde na cobertura da pandemia da Covid-19. Revista Dispositiva. [on-line] Disponível em: $<$ http://periodicos.pucminas.br/index.php/disp ositiva> Dossiê: Comunicação, política e saúde. Editoras Responsáveis: Fernanda Sanglard e Vanessa Veiga de Oliveira. Volume 9, Número 16, Belo Horizonte, dezembro de 2020, p. 6886. Acesso em “dia/mês/ano".

Texto recebido em: 19/07/2020

Texto aprovado em: 17/12/2020 